\title{
LINEAMIENTOS PARA LA ACCIÓN DE LOS LAICOS
}

DOI: https://doi.org/10.52039/seminarios.v53i185.584

Autor: Félix Pecharromán Cebrián. Sacerdote Operario Diocesano que ha desarrollado su labor especialmente en México, actualmente se encuentra en el Hogar Mosén Sol en Majadahonda (Madrid).

Desde su experiencia en la formación de laicos propugna la recuperación del lugar que éstos han de ocupar en la misión. Recuerda que, en épocas, se les ha visto de "rodillas", "mirando al púlpito" y "rascándose el bolsillo". Hoy se impone devolver a los laicos la misión peculiar que tienen en la Iglesia.

Existen deseos reprimidos que no dejamos aflorar, del mismo modo que hay palabras que jamás se llegarán a decir. Pero, de vez en cuando, los deseos aparecen con todo su contenido y las palabras se pronuncian con todo su valor.

Algo de esto es lo que ha ocurrido en nuestros días respecto al deseo de que los Laicos aparecieran en la Iglesia eficientes y esperanzadores y de que la Iglesia dijera su palabra autorizada a favor de ellos, incluso acentuándola en la Nueva versión del Derecho Canónico.

Es muy curioso recorrer el itinerario de esa palabra en la estructura eclesiástica para poderla ubicar en la precisión que le corresponde. Bastaría hojear los primeros escritos de los Padres y contemporáneos para distinguir enseguida esas dos porciones del Pueblo de Dios, en donde se ve que la prioridad está en favor del clero frente a la situación de sometimiento del laico. 
De una manera festiva el Cardenal Gasquet, allá por los años 1914, decía en Londres:

"Un catecúmeno preguntó a un sacerdote católico cuál era la posición del laico en su Iglesia.

- La posición del laico en nuestra Iglesia, respondió el sacerdote, es doble: ponerse de rodillas delante del altar, es la primera; sentarse frente al púlpito, es la segunda.

- El Cardenal Gasquet añade: Olvidó una tercera: meter la mano en el bolsillo y sacar las monedas para la ofrenda".

No sé si en esa misma línea de la ironía se podría interpretar también el dicho:

"La Iglesia es el rebaño de Dios a quien los clérigos esquilan para quedarse con la lana".

Tomando las cosas más cercanas a nosotros podemos ver cuál era la opinión de los Papas respecto al elemento seglar a partir de León XIII.

En una Carta de este Papa a Monseñor Meigan, Arzobispo de Tours, en diciembre de 1898, le decía:

"Es constante y manifiesto que hay en la Iglesia dos órdenes bien distintos por su naturaleza: 'Los Pastores y el rebaño, es decir, los jefes y el pueblo'. El primer orden tiene por función primordial enseñar, gobernar y dirigir a los hombres en la vida; imponer reglas y normas. El otro, tiene por deber estar sometido al primero, es decir, ejecutar sus ordenes y honrarlo".

No sé hasta qué punto hoy se toleraría este lenguaje. Para muchos parecería un insulto y para otros una reliquia arqueológica que hay que conservar como documento de historia.

Pío XI, al estructurar la Acción Católica, da un paso adelante al definir al laico como el participante en el apostolado jerárquico de la Iglesia. Pío XII ${ }_{2}$ en la "Mystici Corporis", nos dirá que los laicos son Iglesia. Pero sería Juan XXIII con la iniciación del Concilio Vaticano II quien diera una respuesta afortunada y completa al ser y al quehacer del laico en la Iglesia. Tanto en la Lumen Gentium como en la Gaudium et Spes encontramos, sin pretenderlo, un verdadero tratado de laicología. Ahí cobran fuerza vibrante y exigencial las capacidades que brotan en estos hombres y mujeres que habiendo recibido el Bautismo y ratificado su fe en la Confirmación, han sido alimentados con el pan de los fuertes para dar razón 
de su esperanza a todo aquel que se la pidiere"1. Y la afirmación tajante de la Lumen Gentium es expresiva, por demás, cuando nos dice:

"Lo que el alma es al cuerpo eso han de ser los cristianos en el mundo"2.

Conscientes, por lo tanto, nosotros los sacerdotes, de esa enorme responsabilidad que les concede su Bautismo, y también experimentadores de los grandes servicios que prestan ellos a la Iglesia, no podremos seguir pensando en esa bipolaridad de fuerzas dentro de la misma institución.

Escribía el Sr. Obispo de Dijón, Dadolle:

"Es posible que en el pasado nosotros mismos, Jerarquía Eclesiástica, no hayamos comprendido suficiente ni completamente vuestro papel. Llamábamos a vuestro bolsillo para nuestras necesidades materiales, a vuestra adhesión y a vuestra inteligencia para la administración de nuestras fábricas; a vuestra fe y a vuestra devoción para escoltar, cirio en mano, las procesiones Eucarísticas.

Durante largos siglos el apostolado fue considerado como una función reservada $\mathrm{y}$, al menos en la práctica, era excesiva la distinción entre la Iglesia docente y la Iglesia discente, entre sacerdotes y laicos.

He oído hablar aquí y en otros lugares (es algo que se oye en todas partes) sobre la cuestión de coordinar los apostolados, el nuestro (jerárquico) y el vuestro, el laico.

Se habla de peligro, de posibles injerencias, ¡ah!, señores, yo sé muy bien que existen toda clase de peligros. Sólo cabe no hacer nada, o no dejar hacer nada, para evitarlos todos. Pero entonces nos resignaremos al mal supremo, a la abstención, que es el oficio de los inútiles a quienes el gran poeta de la Edad Media, Dante, cuando hacía el inventario de su infierno, no quería ni siquiera saludar con la limosna de su mirada: 'Mira y pasa",.

\section{Un poco de valor entre mucho miedo}

El recelo, la desconfianza y la lejanía han tenido enfrentadas estas dos porciones eclesiales a las que hay que dar un destino común y una tarea

\footnotetext{
11 Pe 3, 15.

2 Lumen Gentium, 38.
} 
integrada: evangelizar. Ahí ellos y nosotros los sacerdotes tenemos que coincidir precisamente desde nuestra fuerza bautismal. Que los riesgos existen, ya nos lo decían los obispos mexicanos: "Como todo cambio, el actual no está exento de riesgos... La garantía de acierto está en la unidad de la verdad enseñada auténticamente por el magisterio y en la fidelidad a las disposiciones emanadas de la autoridad jerárquica"3.

Sabemos muy bien que entre la Iglesia subterránea y la Iglesia carismática existe la dialéctica de una mediación equilibrada. Y en la búsqueda de ese quehacer es donde habremos de oponer lo mejor de nuestra iniciativa.

Para nosotros, sacerdotes, no hay duda acerca de la capacidad raíz que asiste al laico para su quehacer evangelizador. Más aún, después del magnífico documento de Pablo VI, Evangelii Nuntiandi, la Lumen Gentium y la Gaudium et Spes, así como la Apostolicam Actuositatem, hablar de esto sería perder el tiempo por demás. Pero nuestra conflictividad surge en el campo de la praxis. A la hora en que hay que confrontar tareas y logros, resultados y programas. Porque la impresión que todos tenemos a partir del Vaticano II es que a los laicos se les ha dado carta de ciudadanía eclesial pero no se les ha refrendado. Los hemos dejado en su potencialidad próxima al acto. En esa que los filósofos creo que llamaban potencia obediencial. Y así hemos visto cómo se han malogrado valores personales que podrían haber sido muy útiles a la comunidad. De donde, que a fuer de honestos, tengamos que interpelarnos con seriedad acerca de muchas cuestiones que tenemos en el aire.

- "¿Va a quedar un lugar claramente discernible para el sacerdote? ¿Quedará algo que sólo el sacerdote podrá hacer?

- ¿Los laicos podrán también arrebatarnos el altar y el púlpito?

- ¿Los templos tendrán esa línea únicamente sacral?

- ¿Cuáles son los cambios fundamentales que constituyen y determinan la situación espiritual de nuestro tiempo?

- ¿Podrán los laicos celebrar la Eucaristía sin sacerdotes siendo ellos los que consagren, algún día?

- ¿También los laicos podrán confesar?"4.

3 Obispos mexicanos. Instrucción Pastoral sobre la Actualización del Apostolado de los Laicos, $\mathrm{n}^{\mathrm{o}} 32$.

${ }^{4}$ Castillo, pág. 159. 
¿Está resuelta la cuestión de la identidad sacerdotal no sólo en lo teórico sino en la praxis existencial? Estas son cuestiones que andan por nuestros ambientes y que preocupan más de lo que aparentemente puede parecer.

Se decía que el Vaticano II había concedido a los obispos todos los poderes, a los laicos todos los placeres y a los sacerdotes todos los deberes. Y cuando la ironía comienza a incidir ambientalmente es porque hay una cierta verdad latente que posibilita su agresividad.

Y será aquí donde tendremos que profundizar para que lo valioso y eficiente siga urgiendo en línea de creatividad y avance. Porque todos sabemos que es fácil cambiar de ideas pero lo que no es tan sencillo es cambiar de ritos, modificar las costumbres e imponer cultos diferentes. Por eso todavía nuestros laicos, aun presumiendo de los ministerios y sabiéndose de memoria lo que Puebla les ha dicho acerca de su clericalización, la verdad es que aún siguen, no sé si por mimetismo o por falta de creatividad, todo el ritual establecido para los clérigos.

En la familia se da este fenómeno experimental. Cuando el niño es pequeño, el papá y la mamá tienen que ofrecerle la mano para que comience a andar, pero lo que nos puede ocurrir es que cuando el niño es joven los padres no le pidan sus manos para caminar con él y no poderse quedar atrás. Puede que en esta misma línea nosotros debiéramos de entender la colaboración del laico y el sacerdote en el campo de la pastoral. Pues me parece que las palabras de Agustín son bastante aleccionadoras a este respecto. Decía él:

"Para vosotros soy obispo, con vosotros soy cristiano. Aquel nombre expresa deber, éste una gracia; aquel indica peligro, éste, salvación"5.

Hoy se está hablando de la promoción de un laicado adulto y ese laicado exige un esfuerzo común y profundo que reclama la sinceridad y la preparación adecuada. Así asumirán los laicos su compromiso temporal y penetrará el espíritu cristiano en las comunidades y ambientes. Escribía Robinson:

"Estoy convencido de que un abismo, cada vez más profundo, ha ido fraguándose entre el sobrenaturalismo tradicional y ortodoxo que hasta ahora ha encuadrado nuestra fe, y las categorías a las que actualmente

\footnotetext{
5 San Agustín, Sermón 340, I, PL 38, 1483.
} 
confiere una significación el mundo 'laico'... Por otra parte, la línea divisoria de la que estoy hablando me parte a mi mismo por la mitad, aunque con el transcurso del tiempo voy viendo que cada vez es menor la parte de mí mismo que se halla a su lado derecho... Y esto no se debe en modo alguno a que haya puesto en duda mi fe o mis responsabilidades religiosas sino a que instintivamente comparto con el humanista su capacidad de aceptar el esquema de pensamiento y el molde de religión en que la fe es únicamente presentada. Siento que tiene razón de rebelarse y experimento una desazón creciente ante el hecho de que la Ortodoxia sea identificación con esta manera de pensar"'.

Es muy posible que el miedo a perder determinados privilegios y el destruir algunos de los mitos que han rodeado el ministerio cultual y la realidad secularizada haya causado retracción y antagonismo entre los sectores del Pueblo de Dios, pero no estará por demás que vayamos haciendo la luz para que se vayan los fantasmas ya que éstos no se van con el ruido sino al amanecer. Para lograr esa tarea es para lo que nos apremian: la desazón, el anhelo, la esperanza y el compromiso.

1.1 La desazón: Somos conscientes del hiato existente entre laicos y clérigos a la hora de las tareas evangelizadoras. A todos nos duele el sentido desagradable de Pablo cuando reprende a la Comunidad de Corinto:

"Cada uno de vosotros dice: 'Yo soy de Pablo', 'yo de Apolo', 'yo de Cefas', 'yo de Cristo'. ¿Acaso se puede dividir a Cristo?"

¿Y no será una de las causas más nefastas en la evangelización entorpecida, esos reinos de Taifa o esas capillitas inexpugnables? Decía Shakespeare en Hamlet: "Cuando los súbditos se quejan el rey los duele". Y es cierto que nos quejamos y es también verdad que nos duele no poder integrar esas comunidades eclesiales en una línea de eficiencia real. Nos duelen los esfuerzos perdidos y las ilusiones rotas de tantos sacerdotes y laicos que aceptaron el compromiso con ilusión, lo comenzaron con celo y lo abandonaron con amargura y desencanto. Y esto, que lo llevamos todos a flor de piel, no es justo que lo queramos conservar. La comezón o el prurito no matan, pero causan situaciones de molestia permanente. Por otra parte, las voces, cada vez más numerosamente críticas de nuestra efi-

\footnotetext{
${ }^{6}$ ROBINSON. Sincero para con Dios, págs. 25 y 26.
}

71 Cor $1,12-13$. 
cacia pastoral, afloran como retos a contestar o como cuestionamientos a decidir.

1.2 El anhelo: Consiguientemente de responder a las interpelaciones nos sitúa en una tesitura exigencial. Porque no hay nada más terrible que sentirse interrogado y no tener nada que decir. Sólo se puede comparar con esta situación angustiosa: el no haber preguntado jamás. Pues aquí podríamos también percibir aquel reproche del novelista alemán, Borchert: "¿Por qué calláis? ¿Por qué? ¿Es que no existe respuesta? ¿Ninguna respuesta?". Y haría falta estar sordo para no escuchar, para no sentirse sobrecogido por ese grito desesperado. De ahí que tendremos que hacer los intentos precisos para que en doble mirada advirtamos las exigencias tanto internas como exteriores para poder remediar la situación real. Pues no se trata de lamentaciones estériles, ni de gimoteos que engendren absentismo y esterilidad. Es el momento de una acción conjunta para que, derribando el muro que dividía a los dos pueblos, sea uno sólo el que se pueda lanzar a actuar hombro con hombro y hombre con hombre.

"Hombres

sobre hombros

de otros hombres;

Hombres

con hombros

para otros hombres;

...Hombros

hombres

hombros

torres.

Un día ya no habrá estrellas lejanas

ni perdidos horizontes".

1.3 La esperanza. Esa será la gran palabra que mueva nuestra tarea y que provoque nuestra inquietud. Tal vez las almas mediocres se salvan porque están vinculadas a las almas santas. El santo contemporáneo es un santo colectivo, un santo fraternal, porque uno se salva conjuntamente y estos santos facilitan a las clases medias la santidad de que ellas son capa-

${ }^{8}$ León Felipe. Antología rota. 
ces, porque tal es su papel, su misión su éxito salvífico. De todos nosotros es conocido el pensamiento de Charles Peguy: 'Hay que salvarse juntos...' Y la espera de esa comunión, la expectativa de ese goce fraternal puede crear situaciones tan convincentes como comprometedoras.

La esperanza es lo más visceral que tiene el hombre. Es también la nota más connotada del cristianismo. Ella se convierte en esa afirmación paulina cabal: "En la esperanza ya estamos salvados" (Rom 8, 24). Y por otro lado, nuestro mundo no espera, ni cree, ni ama. Esos sentimientos tan tiernos le pondrían en peligro de ablandar su corazón. Escribió Paul Claudel, el gran poeta francés que más tarde acabaría por aceptar esa fe que en un principio tan duramente criticaba:

“En este mundo nuestro están de un lado, los sabios, los artistas, los hombres inteligentes, los estadistas, los hombres de negocios, los hombres de mundo, todos los cuales nos aseguran con una perfecta seguridad que Dios no existe; de otra parte están los gazmoños, las viejas beatas, el arte de los viacrucis, la inepcia sofocante de los sermones".

Paul Claudel era el Abraham que creyó esperanzado contra toda esperanza y que nos dejaría esa primorosa obra de teatro llamada "La Anunciación a María”. Y aquí es donde nosotros también pondríamos un acento muy fuerte en lo que constituye el meollo de la piedad popular, tan sentimental y poco crítica como riquísima en expresiones de una intimidad que se contagia. Puebla nos hace una advertencia muy especial a este respecto para que no perdamos de vista esos veneros de comunión. Y el escritor francés, Malegue, escribía a este propósito con acierto exquisito:

“ ¿Cuál es la razón profunda de que el juego espontáneo de las imágenes favorezca con un extraño atractivo adicional precisamente los fines aparentes de la naturaleza humana, los apetitos del momento, lo ficticio, el carnaval?.. Si Dios es, en el corazón de lo real, el impulso fundamental, ¿por qué no estamos apasionados precisamente de Dios? ¿Por qué este deseo de Dios parece menos nuestro que nuestros apetitos terrestres? ¿Cuál es la explicación de este sesgo de oscurecimiento por el cual en los dos hemisferios del mundo empírico, el pensamiento y la acción, Dios ha elegido permanecernos oculto, absconditus? ¿Por qué esta tenuidad, este enflaquecimiento, esta insubstancia, afecta, precisamente al motivo supremo en la inmensa mayoría de las almas quitándole así todas o casi todas sus posibilidades, en el conflicto con las floridas y grasas apariencias terrenales? ¿Por qué el gran impulso jerárquico que arrastra al uni- 
verso hacia arriba se quiebra precisamente al nivel de la conciencia humana? ¿Por qué hace falta tanto heroísmo para ser santo?" 9

1.4. El compromiso: He ahí una urgencia que no podemos dilatar y a la que hay que dar cumplimiento pronto si es que no queremos sucumbir. Pero esta palabra hay que saberla entender bien para que no la queramos deturpar o, lo que sería peor, prostituir. En expresión de Ignace Lepp:

"El compromiso comporta una fe y una donación. Pero una fe perpetua y vigilante, $\mathrm{y}$ una donación constantemente revisada. Es un acto viril, no un arrebato infantil. Tiene el corazón apasionado y una cabeza fría. De otro modo no se podría hablar de compromiso sino de delirio".

Puede que los hombres seamos hombres únicamente en la medida en que proyectamos y amorosamente perseguimos los designios de esa misma proyección. De ahí que en la búsqueda de esa integración hayamos de admitir en primer término la lucidez. Todo escalador tantea sobre guijarros redondos. Su aventura de ascender o descender la montaña corre el riesgo de que esos cantos rodados le jueguen la peor trastada. Esa misma es la aventura que se nos ofrece para integrar la comunidad y para dar a esos hombres laicos el lugar que les corresponde dentro de la Iglesia.

Dios es el que llama y sugiere, pero sus palabras son discretas y nos pide el oído atento para poderlas percibir y saberlas interpretar. Nuestras pasiones gritan, lloran y relinchan y nuestras ansiedades sollozan a voces calladamente.

Para llegar a estas metas es posible que se nos antepongan las razones del miedo. No faltarán en nuestros caminos persuasiones y consejos que pretendan hacernos desistir en el intento de lograr esta comunión fraterna. Sabemos muy bien que los laicos tienen las mismas raíces potenciadoras de santificación que nosotros los sacerdotes: El Ministerio Pontifical, la Profecía y el Realismo. Por esos lineamientos es por los que, con todo derecho, ellos que son Iglesia, pueden y deben obrar en la Iglesia para que la tarea de conversión y reforma prosiga permanentemente. "Ecclesia semper reformanda". Pero nosotros, los hombres y las mujeres de la instalación nos resistimos a cualquier cambio. Nos asusta. Consiguiente-

9 MALEGUE, Las clases medias de la salvación. Cit. Por Charles Moëller en Literatura del siglo XX y cristianismo, vol. II, pág. 288. Gredos. Madrid, 1971. 
mente, en medio de tanto miedo habrá que tener un poco de valor para iniciar esa tarea de rejuvenecimiento. Pues no es sólo necesario renovarse sino también rejuvenecerse. Para este Continente en el que el $75 \%$ de la población tiene menos de 25 años, la juventud es una realidad esperanzadora pero, al mismo tiempo una amenaza, tal vez insuperable si es que no le llegamos a tiempo para poderle contestar a tantas preguntas e inquietudes como se está formulando. A estos hombres y mujeres hay que hablarles en su propio idioma; habrá que responderles con la fuerza con que interrogan en su afán. Entendemos muy bien desde ahí las palabras de Juan Pablo II en la Catedral de México:

"Pertenecer a la Iglesia, vivir en la Iglesia, ser Iglesia, es hoy algo muy exigente. Tal vez no cueste la persecución clara y directa pero podrá costar el desprecio, la indiferencia, la marginación. Es, entonces, fácil y frecuente el peligro del miedo, del cansancio, de la inseguridad. No os dejéis vencer por las tentaciones. No dejéis desvanecerse por alguno de estos sentimientos el vigor y la energía de vuestro "ser Iglesia", esa gracia que hay que pedir y estar prontos a recibirla con una gran pobreza interior, y que hay que comenzar a vivir cada mañana. Y cada día con mayor intensidad"10.

Cerrando estas palabras del Papa, diríamos aquí que el miedo de tener miedo se llama valor.

\section{Un mundo nuevo por mi rostro quiere entrar}

"Al igual que los Sacramentos de la Nueva Ley con los que se alimenta la vida y el apostolado de los fieles, prefiguran el Cielo Nuevo y la Tierra Nueva, así los laicos quedan constituidos en poderosos pregoneros de la fe en las cosas que esperamos, cuando sin vacilación, unen a la vida según la fe, la profesión de esa fe. Tal evangelización, es decir, el anuncio de Cristo pregonado por el testimonio de la vida y por la palabra, adquiere una característica específica y una eficacia singular por el hecho de que se lleva a cabo en las condiciones comunes del mundo" 11.

Esta ha sido la gran sorpresa que el Vaticano nos trajo a los hombres del Siglo XX. Esta es la gran aventura que nos ofrece en la dirección

10 JUAN PABLO II. Alocución en la Catedral de México, 26 de enero de 1979.

11 Lumen Gentium, 35. 
salvadora de ese mismo mundo. Y para que ellos perciban el aliento fraterno de los hermanos en el sacerdocio, el mismo Concilio les dice a éstos:

"Por su parte, los sagrados pastores reconozcan y promuevan la dignidad y responsabilidades de los laicos en la Iglesia. Recurran gustosamente a su prudente consejo, encomiéndenles con confianza cargos en servicio de la Iglesia y denles libertad y oportunidad para actuar; más aún, anímenlos incluso a emprender obras por propia iniciativa. Consideren atentamente ante Cristo, con paterno amor, las iniciativas, los ruegos y los deseos provenientes de los laicos" 12 .

En esa misma línea es en la que Puebla exhorta constantemente a una colaboración y a una participación de los laicos en la transformación de este mundo. Es urgente que los laicos se comprometan en la misión evangelizadora y en la promoción de la justicia. A ellos se les llama a ser los constructores de una sociedad pluralista y a insertarse en los centros de decisión para que el pulso de esa nueva sociedad se perciba en cristiano y pueda llegar a lo que Pio XII llamaba la consecratio mundi. De ahí que habrá que tenerse mucho cuidado de no clericalizarlos sino de promoverlos, de conscientizarlos, de encarnarlos y consiguientemente de convertirlos en levadura en la masa, en fermento de ambientes y en testigos de la verdad; ya que una de las características más acusadas en nuestros días, tanto en el laico como en el sacerdote, ha de ser lo que han llamado parreshía. La audacia para anunciar y denunciar todo aquello que debe ser denunciado y convertido.

El sentido profético hay que despertarlo para que surta los efectos de asombro e impaciencia; pues tal parece que, según Jeremías, en nuestro tiempo, los profetas profetizaron con mentira ${ }^{13}$ y para deshacer ese terrible y nefando error, Puebla nos habla de "hombres del mundo en el corazón de la Iglesia y hombres de Iglesia en el corazón del mundo"14.

Era necesario ese binomio comulgante para deshacer tantas dificultades y era urgente su lectura en la dinámica de la entrega para que nuestro mundo sintiera la presencia de alguien nuevo frente a esta tendencia consumista y placentera del algo nuevo. Estos hombres nuevos serían aquellos a quienes el Señor tocó para enviarlos con el Mensaje de salvación.

\footnotetext{
12 Ibidem, 37.

13 Jer 23, 25.

14 Puebla 786.
} 
Hombres fraternos y cordiales que han sabido prescindir de toda apariencia externa, conscientes del mismo ritmo interior. Hombres y mujeres que hicieron exactamente al revés de la mujer del Evangelio que estaba enferma y deseaba curarse: "Con sólo tocar su manto, me curaré"15. Estos hombres pensaron de distinta manera. Sabiendo que Cristo es una 'enfermedad' y que al que le toca ya no curara jamás, se acercaron a Él, no para poderle tocar sino para que Él los tocara y los pudiera enfermar. Enfermar de esa prodigiosa peste que se llama vitalización. Por eso entenderemos bien que el cristianismo, en nuestros días, tiene que ser profetizado por laicos y sacerdotes en fraternidad conjunta. No con intenciones de suplantación y competencia, sino con la certeza de esa comunión unificante que es la que llevará a la eficacia plausible. Pues a unos y a otros se les aplicarán certeras y exigenciales las palabras de Pablo VI:

"El predicador del Evangelio será aquel que, aun a costa de renuncias y de sacrificios, busca siempre la verdad que debe transmitir a los demás. No vende ni disimula jamás la verdad por el deseo de agradar a los hombres, de causar asombro, ni por originalidad o deseo de aparentar. No rechaza nunca la verdad. No obscurece la verdad revelada por pereza de buscarla, por comodidad, por miedo. No deja de estudiarla. La sirve generosamente sin avasallarla. El Dios de la verdad espera de nosotros que seamos los defensores vigilantes y los predicadores devotos de la misma"16.

Magnífica encomienda para estos hombres y mujeres de mundo que la entienden desde la disponibilidad más abierta y desde el corazón más dispuesto. Estos hombres del mundo que agudizan el oído para percibirla y que esfuerzan la voz para proclamarla. Y estos hombres de Iglesia que silencian todos los ruidos para someter esa verdad a meditación profunda, a recogimiento interpelador y a sobrecogimiento responsable. Estos a quienes describía Diogneto con esa estremecedora sencillez:

"Los cristianos no se distinguen de los demás hombres ni por su país ni por su lenguaje, ni por sus costumbres. Porque no moran en ciudades propias, ni usan lenguaje distinto, ni viven de un modo extraordinario... Pero aunque viven en las ciudades de los griegos y los bárbaros, según le ha correspondido a cada uno de ellos, y siguen las costumbres locales en

\footnotetext{
15 Mt 9, 21.

16 Evangelii nuntiandi, 78.
} 
el vestir y el comer y otros menesteres de la vida, resulta asombrosa la naturaleza de su ciudadanía que ellos manifiestan públicamente, que desmiente a ojos vista lo que de ellos podía esperarse. Viven en sus propios países, pero únicamente como transeúntes; soportan todas las cargas como ciudadanos, y sufren todas las penalidades como extranjeros. Cada país extranjero es una patria para ellos, y cada patria les es un país extranjero... Obedecen las leyes instituidas, y van más allá de las leyes en su propia vida... En una palabra, como el alma está en el cuerpo así los cristianos están en el mundo El alma está encerrada en el cuerpo y sin embargo sostiene el cuerpo; así también los cristianos están en este mundo como en una cárcel, y sin embargo sostienen el mundo. Así es de elevada la misión que Dios les ha señalado, y no les está permitido rehuirla"17.

Se nos antoja que en esas palabras se continúan las de la Carta de Pablo a los Corintios cuando les decía:

“...en la palabra de verdad, en el poder de Dios; mediante las armas de la justicia; las de la derecha y las de la izquierda; en gloria e ignominia, en calumnia y en buena fama; tenidos como impostores, siendo veraces; como desconocidos, aunque bien conocidos; como quienes están en la muerte, pero vivos; como castigados, aunque no condenados a muerte; como pobres, aunque enriquecemos a muchos; como quienes nada tienen, aunque todo lo poseemos"18.

En esa aparente contradicción o, mejor, en la paradoja, que es siempre la geografía del amor y de la vida, es donde la comunidad cristiana tiene que dar testimonio comulgante para que la fe se extienda. Porque..."La identidad cristiana no es la identidad humana sin más, porque no se trata, ante todo, de un acrecentamiento de saberes o de valores inmediatamente constatables o separables de la propia existencia personal, sino que se trata primordialmente de un orden de realidad nueva, de una oferta de salvación que se percibe en audiencia de Dios, que se detecta como valiosa en seguimiento de su llamada y que se convierte en suprema necesidad en nuestra vida cuando hemos entrado en la lógica de sus exigencias para con nosotros mismos y para con nuestros prójimos"19.

\footnotetext{
17 Carta a Diogneto.

182 Cor 6, 7-11.

19 GONZÁLEZ DE CARDEDAL, O. Cambios históricos e identidad cristiana, pág. 38. Sígueme. Salamanca.
} 
Conscientes de esas exigencias y sabedores de nuestras penurias, para el logro de esas realidades comulgantes e identificadores, habremos de recurrir también al camino de la paradoja y traer a la memoria aquellas palabras de D. Miguel de Unamuno, el eterno paradójico e inconformista, donquijotesco y cristiano.

"Una vez, ¿te acuerdas? Vimos ocho o diez mozos reunirse y seguir a uno que les decía: ‘`Vamos a hacer una barbaridad!' Y eso es lo que tú y yo anhelamos: que el pueblo se apiñe, y gritando: '¡Vamos a hacer una barbaridad!', se ponga en marcha; y si algún bachiller, algún barbero, algún cura, algún canónigo o algún duque les detuviese para decirles: ‘Hijos míos!, está bien: Os veo henchidos de heroísmo, llenos de santa indignación; también yo voy con vosotros; pero antes de ir todos, y yo con vosotros, a hacer esa barbaridad, ¿no os parece que debíamos ponernos de acuerdo respecto a la barbaridad que vamos a hacer? ¿Qué barbaridad va a ser ésa?' Y si alguno de esos malandrines, que he dicho, les detuviese para decirles tal cosa, deberían derribarle al punto y pasar todos sobre él pisoteándole, y ya comenzaba la heroica barbaridad.

¿No crees, mi amigo, que hay por ahí muchas almas solitarias a las que el corazón les pide alguna barbaridad, algo de que revienten?"20

Tal vez, la gran barbaridad a realizar por estos mozos, por esta gente nueva que ha emprendido la tarea de estar en el corazón tanto de la Iglesia como del mundo, será llevar a cabo los deseos de los obispos cuando hicieron su profesión de fe en Puebla acerca de la civilización del amor. Para lograr esta barbaridad, este absurdo para muchos, es para lo que se necesitan estos hombres renovados. Hombres y mujeres de los movimientos laicos en la Iglesia que tienen por misión cambiar la faz de la tierra hostil y fría en fraterna y cordial. Los hombres de la utopía frente a los hombres de la lógica. Pues la utopía, en términos actuales, "manifiesta la permanente ansia de renovación, regeneración y perfeccionamiento buscados por el hombre; la utopía no parte de la nada, parte de una experiencia y anhelo humanos" 21 .

20 UNAMUNO, M. Prólogo de Vida de D. Quijote y Sancho. Aguilar. Madrid.

${ }^{21}$ BOFF, L. La vida más allá de la muerte, pág. 18. 
Por eso no nos es difícil entender el compromiso que en los movimientos laicales les cabe a ellos directamente. Así dicen los obispos mexicanos en el documento citado:

"El gobierno de las organizaciones de los apostolados seglares pertenece a los laicos. A ellos compete la toma de decisiones en la planeación y ejecución de los trabajos, conforme a sus fines, la responsabilidad de los mismos trabajos y el manejo de los recursos económicos que les son propios. La presencia de asistentes eclesiásticos ha de ser eminentemente sacerdotal; ellos deben siempre promover el diálogo directo de los laicos con sus obispos y con otros movimientos; cuidar especialmente de cultivar y suscitar la amistad entre todos para que prevalezca siempre el espíritu de caridad cristiana. Las relaciones entre laicos, religiosos y sacerdotes han de encontrarse precisamente a través de la integración y participación en la comunidad".

La Lumen Gentium seguirá diciendo:

"A los Laicos corresponde, por propia vocación, tratar de obtener el Reino de Dios estimando los asuntos temporales y ordenándolos según Dios. Viven en el siglo es decir, en todos y cada uno de los deberes y ocupaciones del mundo y en las condiciones ordinarias de la vida familiar y social, con las que su existencia está entretenida"22.

Y este mundo, "que está todo él puesto en el maligno"23, exigirá de estos hombres verdaderas aventuras o barbaridades para no acomodarse a él y, lo que es más desafiante, para transformarlo de salvaje en humano y de humano en divino. Para ello, ciertamente, necesitarán la fuerza del Espíritu recibida en la confirmación; la presencia estimulante de la Eucaristía y el carisma específico de la seglaridad hecha matrimonio o sacerdocio al servicio de los hermanos. Y a estos hombres de la barbaridad, con los mejores deseos de eficacia les decimos desde aquí:

"¡A vosotros, que de antemano tenéis perdida la partida, nuestra esperanza!"

${ }^{22} \mathrm{LG}, \mathrm{n}^{\circ} 31$.

231 Jn 5,9 . 


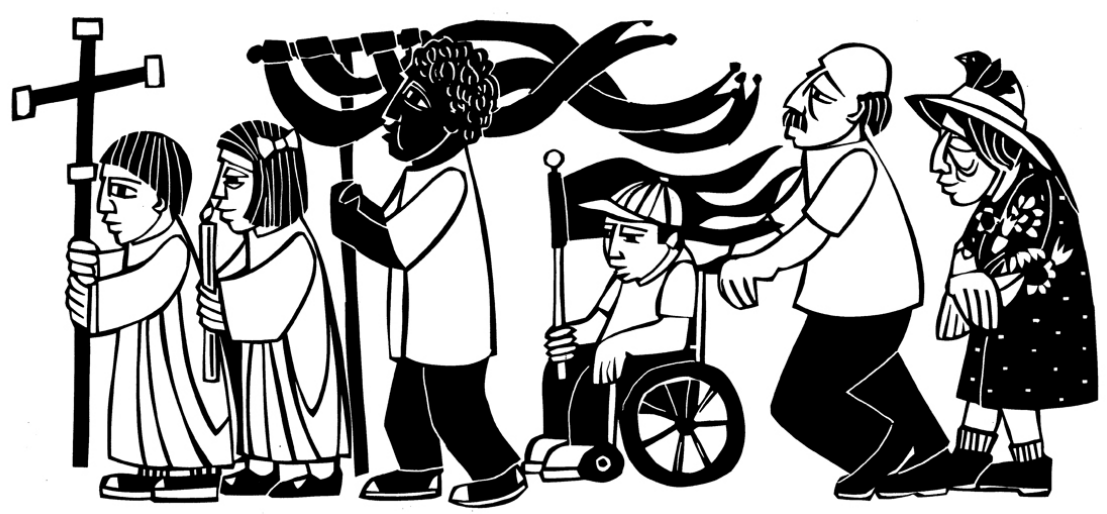

